\title{
The Relationships among Buyers' Perceived Risk, Exhibitors' Brand Equity, Purchase Postponement and Switching Intention-From the Perspectives of Perceived Risk Theory and Expectancy Theory
}

\author{
Chao-Chih Hung, Wen-Long Zhuang, Che-Huei Lin \\ BOARKE MACHINE CO., LTD. \\ National Chiayi University, Taiwan \\ abow38@yahoo.com.tw
}

\begin{abstract}
This study explores the effects of buyers' perceived risk on their purchase postponement and switching intention in an international industrial fair, as well as examines the moderating effect of exhibitors' brand equity on the above relationships. This study uses the purposive sampling method to survey buyers of the famous International Woodworking Machine Fair in Hanover, Germany. Of the 200 surveys distributed, 105 valid questionnaires were returned, representing a response rate of 52.50\%. Analytical results show that higher buyers' perceived risk is associated with buyers' higher purchase postponement, and stronger switching intention. Furthermore, when facing high-brand equity exhibitors' products, if buyers perceive low risk of use, they are unlikely to delay purchase and switch suppliers; in contrast, if they perceive high risk of use, they are more likely to delay purchase and switch suppliers. Finally, when buyers face low-brand equity exhibitors' products, if they perceive low risk of use, they will delay purchase and switch suppliers; in contrast, if they perceive high risk of use, they will tend not to delay purchase and switch suppliers.
\end{abstract}

Keywords: Perceived Risk, Brand Equity, Purchase Postponement, Switching Intention

\section{Introduction}

Exhibitions have become increasingly important to companies. In related studies, Kirchgeorg, Jung, \& Klante (2010) noted that an increasing number of exhibitors are seeking the conditions to ensure future success, and exhibitions are a major tool for companies to achieve sales objectives and contact with buyers (Blythe, 2010). In addition, many marketing experts believe exhibitions represent a level playing field and make a small company appear to be bigger (Tanner, 2002). Therefore, if exhibitors can take advantage of each trade fair opportunity and dedicate toward marketing their own brands, their orders will increase consistently and a small company may perhaps transform to become a large company. Previous researches on exhibition mostly dealt with trade show performance (i.e., overall success, sales-related, image-buildings, 
information-gatherings and so on) (e.g., Dekimpe, Francois, Gopalakrishna, Lilien, \& Van den Bulte, 1997; Gopalakrishna \& Lilien, 1995; Gopalakrishna, Lilien, Williams, \& Sequeira 1995; Hansen, 2004; Hung, Lee, \& Zhuang, 2015; Kerin \& Cron, 1987; Lee \& Kim, 2008; Lee, Lee, \& Yoon, 2013; Li, 2006, 2007; Seringhaus \& Rosson, 2001; Tanner, 2002), but none addressed the negative issues arising from trade fairs. In fact, fair visitors' purchase could be delayed because there are too many exhibitor products to choose from. Moreover, if buyers purchased an unsuitable machine prior to the fair, they could be trying to find a replacement product at the fair. As a result, they may choose to switch supplier.

If exhibitors are concerned about visitors' purchase postponement and switching intention, they have to understand the reasons affecting buyers' intention of the aforementioned behaviors. Previous studies classified perceived risk as the key factor affecting consumers' decisions and behaviors (e.g., Featherman \& Pavlou, 2003; Fraedrich \& Ferrell, 1992; Liao, Lin, \& Liu, 2010; Mitchell, 1992; Pavlou, 2003). Therefore, if fair visitors perceive a high risk that the exhibitors' products would be unsuitable, their purchase postponement and switching intention would very likely be affected. Worth noting is that brand equity is an important factor for businesses to maintain competitive advantage and profitability (Aaker, 1991). If exhibitors possess high brand equity, they should still have competitive advantages in a hyper-competitive exhibition. Therefore, would buyers' perceived risk affect their purchase postponement and switching intention? Would there be differences caused by exhibitors' brand equity? According to the above, this study tried to fill the said research gap and surveyed the visitors of the International Woodworking Machine Fair in Hanover, Germany to discuss the effect of buyers' perceived risk on exhibitors' purchase postponement and switching intention, as well as the moderating role of exhibitors' brand equity on the above relationships.

\section{Literature Review}

Related Studies of Exhibition: Previous researches on exhibition mostly dealt with trade show performance (i.e., overall success, sales-related, image-buildings, information-gatherings and so on) (e.g., Dekimpe et al., 1997; Gopalakrishna \& Lilien, 1995; Gopalakrishna et al., 1995; Hansen, 2004; Kerin \& Cron, 1987; Lee \& Kim, 2008; Li, 2006, 2007; Seringhaus \& Rosson 2001; Tanner, 2002). Godar \& O'Connor (2001) discussed the motivation of industrial buyers in attending trade shows and used the concept of buying centers to establish the sellers' classification of visitors. Buyers were classified into existing buyers, potential customers, and non-buyers and the motivation of these 3 groups was discussed. Kirchgeorg et al. (2010) explored the major factors turning exhibitions into a marketing tool before 2020. The study found that trade shows are an important marketing tool and that the organizers of the shows are in a highly competitive market. While the above studies focus on the perspectives of exhibitors or organizers, this study examines the effect of buyers' perceived risk on their purchase postponement and switching intention, and examines moderating role of brand equity from the standpoint of visitors. 
Expectancy Theory: The expectancy theory is a motivation theory based on personal expectations. The theory proposes that a person will decide to behave or act in a certain way because they are motivated to select a specific behavior over other behaviors due to what they expect the result of that selected behavior will be (Vroom, 1964). The individual makes choices based on estimates of how well the expected results of a given behavior are going to match up with or eventually lead to the desired results. Motivation is a product of the individual's expectancy that a certain effort will lead to the intended performance, the instrumentality of this performance to achieving a certain result, and the desirability of this result for the individual. According to the expectancy theory, (Mitchell \& Biglan, 1971; Vroom, 1964), affected by two types of expectations, the individual would be encouraged to adopt a specific behavior. The first type of expectancy is the belief that one's effort will result in attainment of desired performance goals and the second type of expectancy is the belief that a person will receive a reward if the performance expectation is met. These two expectancies interact with each other and with the valence (attractiveness) of outcomes to determine the overall level of motivation (Harder, 1991).

Purchase Postponement: Greenleaf \& Lehmann (1995) found that consumers would delay purchase decisions if they confront difficulties when choosing from multiple options. The reason for this is that people are sometimes unsure which alternative they prefer (because the alternatives are similar in attractiveness), thereby causing purchasing delay (Dhar, 1997). Jacoby \& Morrin (1998) noted that if consumers are confused about the product choices, suboptimal purchase decision is unlikely as they need more time to formulate decisions or they would delay purchase or even abandon purchase. A research of Dutta \& Biswas (2005) found that to enhance consumers' purchase value, retailers might provide a low price guarantee. As a result, consumers may defer their purchase in order to search for products with much lower prices. Walsh, Hennig-Thurau, \& Mitchell (2007) discovered that consumers' confusion proneness would cause purchase delay. For international industrial fair visitors, they have to spend time evaluating and comparing products before choosing the most suitable one because there are generally a variety of products displayed by the exhibitors. In other words, purchase postponement is likely to occur in international industrial fairs.

Switching Intention: Switching intention denotes the propensity to terminate the primary supplier (buyer-seller) relationship (Ping, 1994). According to Keaveney (1995), switching intention is important toward understanding consumer behaviors. The mental inclination indicates that customers are switching to another and terminating the purchasing from the present brand. Sloot \& Verhoef (2008) defined switching intention as the degree to which a consumer is likely to switch to another brand within the category in the case of a brand delisting. For international industrial fair visitors, if they are inclined to stop using products from the major supplier, they could switch to products of other suppliers. Therefore, they would prefer to search for and compare similar products displayed in the fair. 
Perceived Risk, Purchase Postponement and Switching Intention: Perceived risk was originally developed from the theories of psychology by Bauer (1960), who viewed consumer behavior as an instance of "risk taking" because consumers bear some degree of risks when considering the purchase of a product if they are unable to ascertain a product's performance. Cox (1967) elaborated Bauer's conceptualization and further proposed the perceived risk theory, pointing out the consumer's uncertainty that all of his buying goals can be achieved or expectations of unfavorable purchase outcomes would lead to perceived risk. Dowling \& Staelin (1994) defined perceived risk as a consumer's perceptions of the uncertainty and adverse consequences of engaging in an activity, while Sweeney, Soutar \& Johnson (1999) viewed perceived risk as a subjective expectation of loss. Perceived risk is a form of uncertainty resulting from the negative results caused by individual behaviors; increasing uncertainty and higher degree of eliciting negative results are associated with higher degree of perceived risk (Campbell \& Goodstein, 2001; Featherman \& Pavlou, 2003). This study adopts Dowling \& Staelin's (1994) conceptualization that in the international machinery trade fair setting, buyers' perceived risk is the expectation of likelihood that they would run into problems on use after they purchase an exhibitor's product.

From the perspective of the perceived risk theory (Cox, 1967), if buyers are unable to determine what type of purchase would meet their purchase goals or are concerned that the experience of product use may fail their expectations, they would perceive low value about the product (Wu, Vassileva, Noorian \& Zhao, 2015) and become uncertain and be unable to place orders immediately. According to the above, we posit the following hypothesis:

H1: the higher buyers' perceived risk on exhibitors' products is, the more their purchase postponement will be.

Grewal, Iyer, Gotlieb and Levy (2007) argued that the post-purchase risk has a negative effect on repeat behavior intentions. According to the perceived risk theory (Cox, 1967), if buyers are uncertain about their purchase goals or concerned that the exhibitors' products may fail their expectations, they may wish to purchase other more suitable products. Exhibitors in trade fairs provide machinery and equipment that have different functions but achieve similar objectives. When buyers perceive these products as low-risk products, they may intend to switch supplier. According to the above, we posit the following hypothesis:

H2: The Higher buyers' perceived risk on exhibitors' products is, the more switching supplier's intention will be.

Moderating Role of Brand Equity: Brand equity is one of the most valuable intangible assets of a company. The concept of brand equity was first used in U.S.' advertising sector in the early 80s (Barwise, 1993) and then drew heated discussion in the scholastic field in the late 80s (Keller, 1993). Brand equity represents the added value with which a given brand endows a product (Farquhar, 1989; Yoo \& Donth, 2001). Keller (1993) defined brand equity from the customer perspective as the differential effect that brand knowledge has on consumer response to the marketing of that brand. Aaker (1995) defined brand equity as a set of brand assets 
and liabilities linked to a brand that add to or subtract from the value provided by the product or service. Brand assets include aspects like brand loyalty, brand awareness, perceived quality, brand association, and over accessory assets (like patents and trademarks). Brand equity is the added value of product and service. This added value may be revealed in how customers consider, feel and act with the respect to a brand, as well as the prices, market share and profitability that the brand commands for the company (Kotler \& Keller, 2009). This study adopts Farquhar (1989) and Yoo \& Donth's (2001) viewpoints, that for exhibitors of international industrial fairs, the brand can add to or subtract from the fair attendees' perception of product utility and value.

Although buyers' perceived risk would raise their purchase postponement and switching intention, these relationships depend on exhibitors' brand equity. According to the expectancy theory, high brand equity products give buyers a perception that the price and quality is higher, and it tells that product quality is fair for the price (Kim \& Hyun, 2011). If buyers perceive high brand equity exhibitors' products as having high risk on use, they expect to subsequently spend more on the products. Therefore, buyers are very likely to postpone their purchase or switch suppliers. In contrast, if buyers perceive high brand equity exhibitors' products as having low risk on use, they expect to subsequently spend less on the maintenance cost. Therefore, buyers are very unlikely to postpone their purchase or switch suppliers. According to the expectancy theory, low brand equity products give buyers a perception that the price and quality are inferior. If buyers perceive low brand equity exhibitors' products as having high risk on use, they are unlikely to postpone purchase or switch suppliers due to the low price and lack of unhappy experience in the past. In contrast, if buyers perceive low brand equity exhibitors' products as having low risk on use and if other low-price machines and equipment are offered by other low brand equity, buyers are very likely to postpone their purchase or switch suppliers even though they did not have previously unhappy experience on use. According to the above, we posit the following hypotheses:

H3: exhibitors' brand equity has a positive moderating effect on the relationship between buyers' perceived risk and purchase postponement

H4: exhibitors' brand equity has a positive moderating effect on the relationship between buyers' perceived risk and switching intention

\section{Methodology}

Participants and Sampling Methods: Considering that LIGNA is a top-notch woodworking and wood processing industry affair, this study uses the purposive sampling method to survey buyers from around the world during the famous international woodworking machine fair in 2013. In total, 200 surveys were distributed and 111 were returned. After eliminating 6 invalid surveys, valid surveys totaled 105 (response rate $52.50 \%$ ). Among the 105 respondents, most had 5-9 years of job experience (40.00\%), followed by 10-14 
years (26.70\%). Most respondents had a current industry in home furniture manufacturing (43.80\%), followed by machine sales (18.10\%) and machine manufacturing (16.20\%). As for job title, most respondents were general manager (36.20\%), followed by business owner $(27.60 \%)$.

According to the above literature review and hypotheses, the research framework of this study is presented in Figure 1.

Figure 1: Conceptual Framework

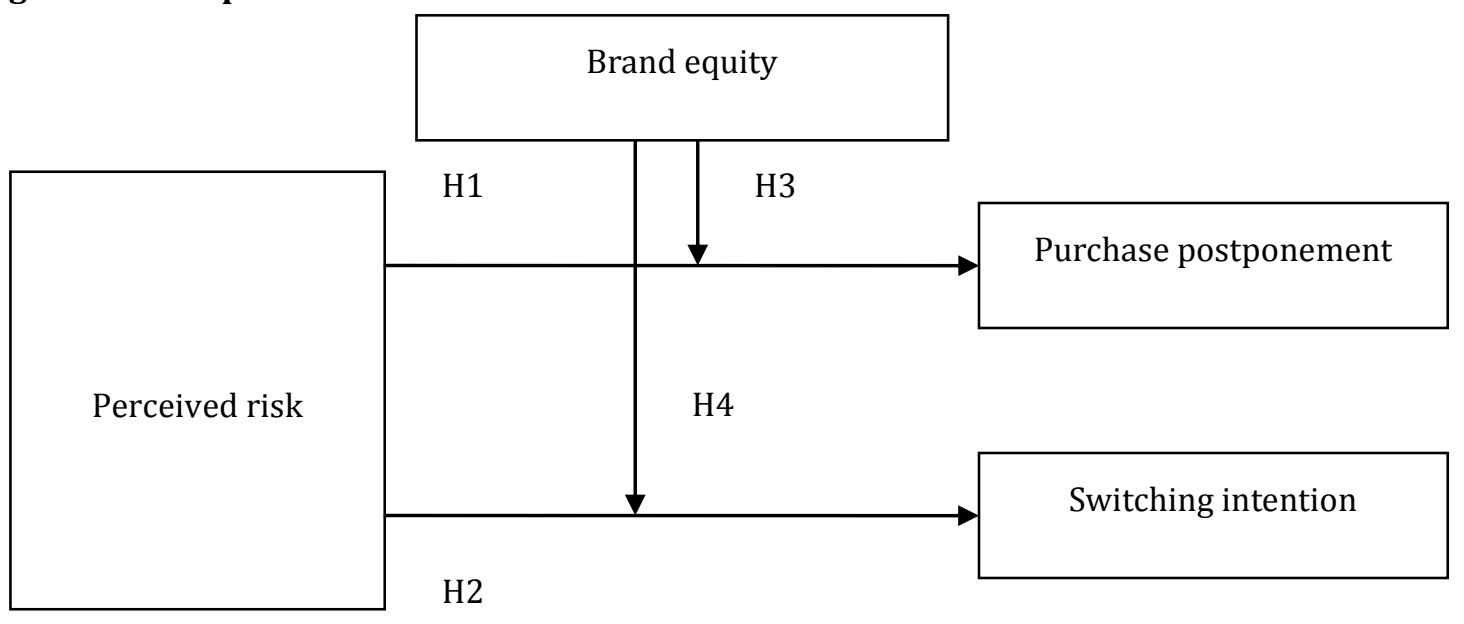

Operational Definitions, Measurement Tools of Research Variables: Details of the operational definitions and measurement tools of the major research variables in this study are provided as follows:

Purchase Postponement: This study defines purchase postponement as "buyers at international industrial fairs have many products to choose from. They must spend time to evaluate, compare, and choose the most suitable products, which may elicit purchase postponement." Referencing Walsh et al. (2007), this study used 4 items to measure purchase postponement: "It is difficult for me to make decision on buying the same machine from the same seller in the trade fair", "When I have intention to purchase, I will like to delay this decision", "I tend to postpone purchasing the same product from the same seller in the trade fair" and "In the trade fair, there are so many choices; so to purchase will take longer than expected". The respondents were requested to indicate on a 5 -point Likert scale ( $1=$ 'totally disagree' to $5=$ 'totally agree') the degree to which they perceived their purchase intention.

Switching Intention: This study defines switching intention as "when international trade fair buyers do not intend to continue using products from their existing supplier, they switch to other companies' products." Referencing Oliver \& Swan (1989), this study used 3 items to measure switching intention: "I don't want to buy the same product from the same seller; I want to buy other product from a new seller in the trade fair", "Probably, not to buy the same product from the same seller; I will like to buy other product from a new seller in the trade fair" and "Certainly, I don't want to buy the same product from the same seller; I will like to buy other product from a new seller in the trade fair". The respondents were requested to indicate on a 5-point 
Likert scale (1='totally disagree' to $5=$ 'totally agree') the degree to which they perceived their purchase intention.

Perceived Risk: In this study, perceived risk is operationally defined as the level that international industrial fair buyers perceived the risk on product use when they consider purchasing exhibitors' products. Referencing Sinha \& Batra (1999), This study used 4 items to measure perceived risk: "When I choose the same brand from the same seller, it is a serious mistake if I buy a wrong machine in the trade fair;" "In the trade fair, I will go too wrong if I buy the wrong model from the same seller;" If, after I bought the same model from the same seller, if my choice proved to be wrong, I would be really upset;" and "When I choose the same model from the same seller, I still will make that choice very carefully in the trade fair." The respondents were requested to indicate on a 5 -point Likert scale $(1=$ 'totally disagree' to $5=$ 'totally agree') the degree to which they perceived the risks of exhibitor's products.

Brand Equity: In this study, brand equity is operationally defined as the feelings of performance and value enhancement perceived by exhibition booth visitors elicited by the exhibitor's brand name. To measure brand equity, a 4-item scale was adopted by Yoo \& Donth (2001). Items included: "Although each brand is very similar, I still insist on purchasing products from this brand;" "Although other brands have similar characteristics with this brand, I still prefer to buy this brand;" If other brands are equally good as this brand, I still prefer to buy this brand;" and "If other brands are not very different from this brand, buying this brand is a smarter choice." The respondents were requested to indicate on a 5-point Likert scale (1='totally disagree' to $5=$ 'totally agree') the degree to which they perceived the exhibitor's brand equity.

Control Variables: This study controlled variables like buyers' work experience, current industry and job title as these factors are considered influential of purchase postponement and switching intention.

Reliability and Validity: Both the reliability and the validity of the measures were examined. This work used Cronbach's $\alpha$ to assess the reliability of the measures. Cronbach's $\alpha$ was $<0.7$ and item-total correlation was $<0.45$. The standards described above were used to delete items. Cronbach's $\alpha$ was 0.86 for purchase postponement, 0.92 for switching intention, 0.89 for perceived risk and 0.88 for brand equity. Each scale demonstrated satisfactory reliability ( $\alpha$ exceeding 0.70 ). In order to minimize the common method variance (CMV) bias, Podsakoff, Mackenzie, Lee \& Podsakoff (2003) had suggested the following preventive methods: (1) adding reverse items in the questionnaire, (2) randomly arranging measuring items in the questionnaire, (3) concealing the purpose of the study, and (4) concealing the relationship between questions. Thus, the questionnaire was formulated based on the principles suggested by Podsakoff et al. (2003), including reverse items, random item arrangement, anonymity, and concealing the purpose of the study.

Furthermore, this study followed the procedure proposed by Noble \& Mokwa (1999), and performed a series of confirmatory factor analyses on construct measures and related items using the AMOS 6.0 software. Generally, the measures were acceptable, with all of the constructs having overall acceptable fit indices. The 
values of average variance extracted (AVE) were 0.61 for purchase postponement, 0.80 for switching intention, 0.69 for perceived risk and 0.66 for brand equity. All constructs exceeded a suggested critical value of 0.50 (Fornell \& Larcker, 1981). The analytical results validated the convergent validity of the constructs. Discriminant validity can be established by demonstrating that the AVE by a particular construct from its indicators is greater than its squared correlation (shared variance) with another construct (Fornell \& Larcker, 1981). Each squared phi coefficient between purchase postponement and every other variable was examined. The analytical results indicated that almost each construct's AVE was greater than its shared variance with purchase postponement. The shared variances between purchase postponement and perceived risk, switching intention, and brand equity were $0.06,0.11$ and 0.37 , respectively. The analytical results confirmed the discriminant validity of the constructs.

\section{Results}

The means, standard deviations, bivariate correlations among the variables are reported in Table 1.

Table 1: Descriptive Statistics and Correlation Coefficients

\begin{tabular}{lllllll}
\hline Variable & Means & S.D. & $\mathbf{1}$ & $\mathbf{2}$ & $\mathbf{3}$ & $\mathbf{4}$ \\
\hline 1. Perceived risk & 3.51 & 0.78 & 1 & & & \\
2. Purchase postponement & 3.04 & 0.78 & $.251^{* *}$ & 1 & & \\
3. Switching intention & 3.27 & 0.84 & $.248^{*}$ & $.609^{* *}$ & 1 & \\
4. Brand equity & 3.33 & 0.81 & $.591^{* *}$ & $.329^{* *}$ & .176 & 1 \\
\hline
\end{tabular}

Note: $\mathrm{n}=105 .{ }^{*} \mathrm{p}<0.05,{ }^{* *} \mathrm{p}<0.01$

The Effect of Perceived Risk on Purchase Postponement and Switching Intention: Hypothesis 1 concerns the relationship between perceived risk and purchase postponement. Table 2 presents the results of multiple regression analyses, with perceived risk as independent variable, purchase postponement as the dependent variable, and job experience, current industry, and job title as the control variables. Table 2 shows that perceived risk has a positive and significant effect on purchase postponement $(\beta=0.25, p<.05)$. Therefore, Hypothesis 1 is supported. 
Table 2: Multiple Regression Analysis of Brand Equity for Purchase Intention, Purchase Postponement and Switching Intention

\begin{tabular}{lll}
\hline $\begin{array}{ll}\text { Dependent variable } \\
\text { statistics Independent variables }\end{array}$ & Purchase postponement & Switching intention \\
\hline Job experience & $-0.25^{*}$ & $-0.25^{* *}$ \\
Current industry & 0.05 & $0.27^{* *}$ \\
Job title & -0.15 & $-0.40^{* * *}$ \\
Perceived risk & $0.25^{*}$ & $0.28^{* *}$ \\
$R^{2}$ & 0.14 & 0.38 \\
Adjusted $R^{2}$ & 0.10 & 0.36 \\
F & $3.80^{* *}$ & $15.13^{* * *}$ \\
\hline
\end{tabular}

Note: all statistical figures are $\beta$ values; ${ }^{*} p<.05,{ }^{* *} p<.01,{ }^{* * *} p<.001$.

Hypothesis 2 concerns the relationship between perceived risk and switching intention. Table 2 presents the results of multiple regression analyses, with perceived risk as independent variable, switching intention as the dependent variable, and job experience, current industry, and job title as the control variables. Table 2 shows that perceived risk has a positive and significant effect on switching intention $(\beta=0.28, p<.01)$. Therefore, Hypothesis 2 is supported.

The Moderating Effect of Brand Equity: Hypothesis 3 concerns whether brand equity moderates the relationship between perceived risk and purchase postponement. Table 3 shows: the interaction between perceived risk and brand equity significantly predicted purchase postponement $(\beta=1.98, p<.01)$. As shown in Figure 2, when buyers face high brand equity exhibitors' products, if they perceive high risk on using exhibitors' products, they will tend to delay the purchase; in contrast, if buyers perceive low risk on using exhibitors' products, they will tend not to delay the purchase. When buyers face low brand equity exhibitors' products, if they perceive high risk on using exhibitors' products, they will tend not to delay the purchase; in contrast, if buyers perceive low risk on using exhibitors' products, they will tend to delay the purchase. As such, Hypothesis 3 is supported. 
Table 3: Moderating Effect of Brand Equity

\begin{tabular}{lll}
\hline Dependent variable & Purchase postponement & Switching intention \\
Statistics Independent Variables & & \\
\hline Job experience & -0.14 & $-0.20^{*}$ \\
Current industry & 0.07 & $0.27^{* *}$ \\
Job title & $-0.21^{*}$ & $-0.42^{* * *}$ \\
Perceived risk & $-0.90^{* *}$ & -0.31 \\
Brand equity & $-0.88^{*}$ & -0.59 \\
Perceived risk $\times$ Brand equity & $1.98^{* *}$ & $1.107^{*}$ \\
$R^{2}$ & 0.28 & 0.42 \\
Adjusted $R^{2}$ & 0.23 & 0.38 \\
F & $6.00^{* * *}$ & $11.30^{* * *}$ \\
\hline
\end{tabular}

Note: all statistical figures are $\beta$ values; ${ }^{*} p<.05,{ }^{* *} p<.01,{ }^{* * *} p<.001$.

Hypothesis 4 concerns whether brand equity moderates the relationship between perceived risk and switching intention. Table 3 shows: the interaction between perceived risk and brand equity significantly predicted switching intention $(\beta=1.11, p<.05)$. As shown in Figure 3 , when buyers face high brand equity exhibitors' products, if they perceive high risk on using exhibitors' products, they will tend to switch suppliers; in contrast, if buyers perceive low risk on using exhibitors' products, they will tend not to switch suppliers. When buyers face low-brand equity exhibitors' products, if they perceive high risk on using exhibitors' products, they will tend not to switch suppliers; in contrast, if buyers perceive low risk on using exhibitors' products, they will tend to switch suppliers. As such, Hypothesis 4 is supported.

Figure 2: Moderating Effect of Brand Equity on the Relationship between Perceived Risk and Purchase Postponement

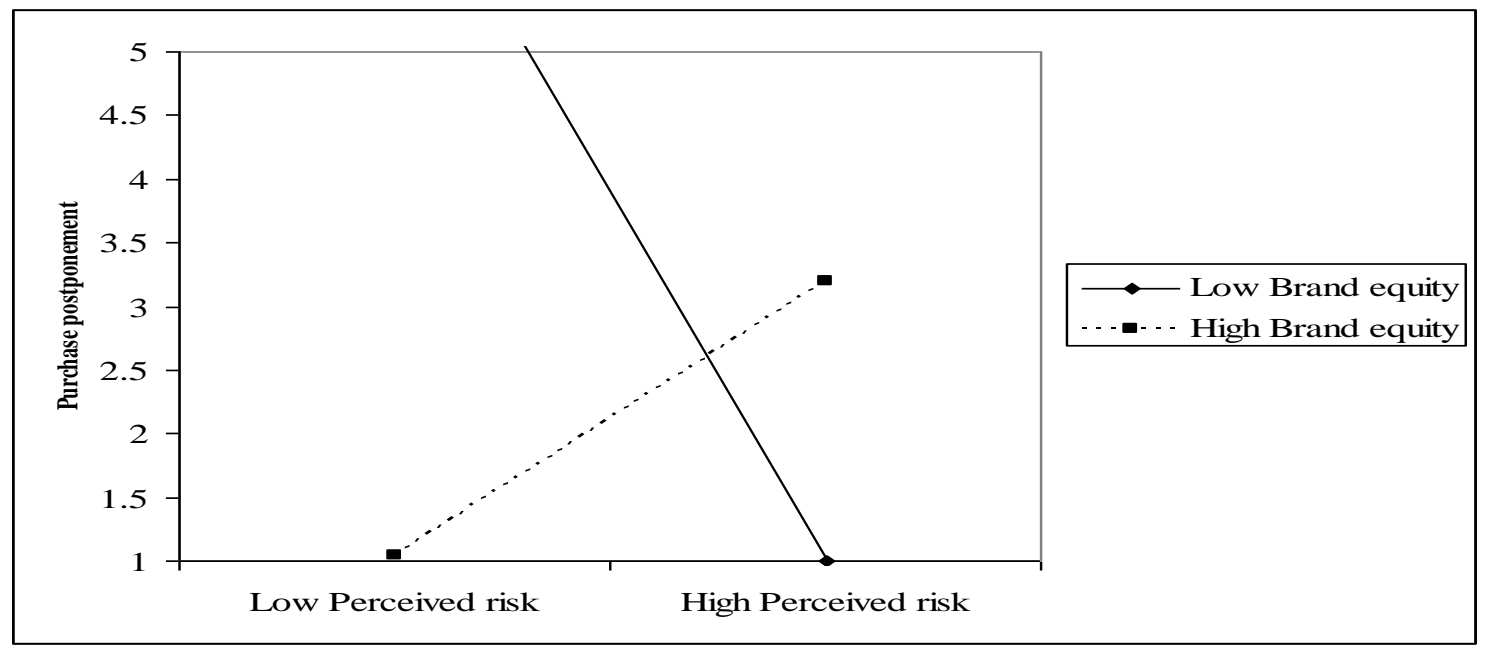


Figure 3: Moderating Effect of Brand Equity on the Relationship between Perceived Risk and Switching

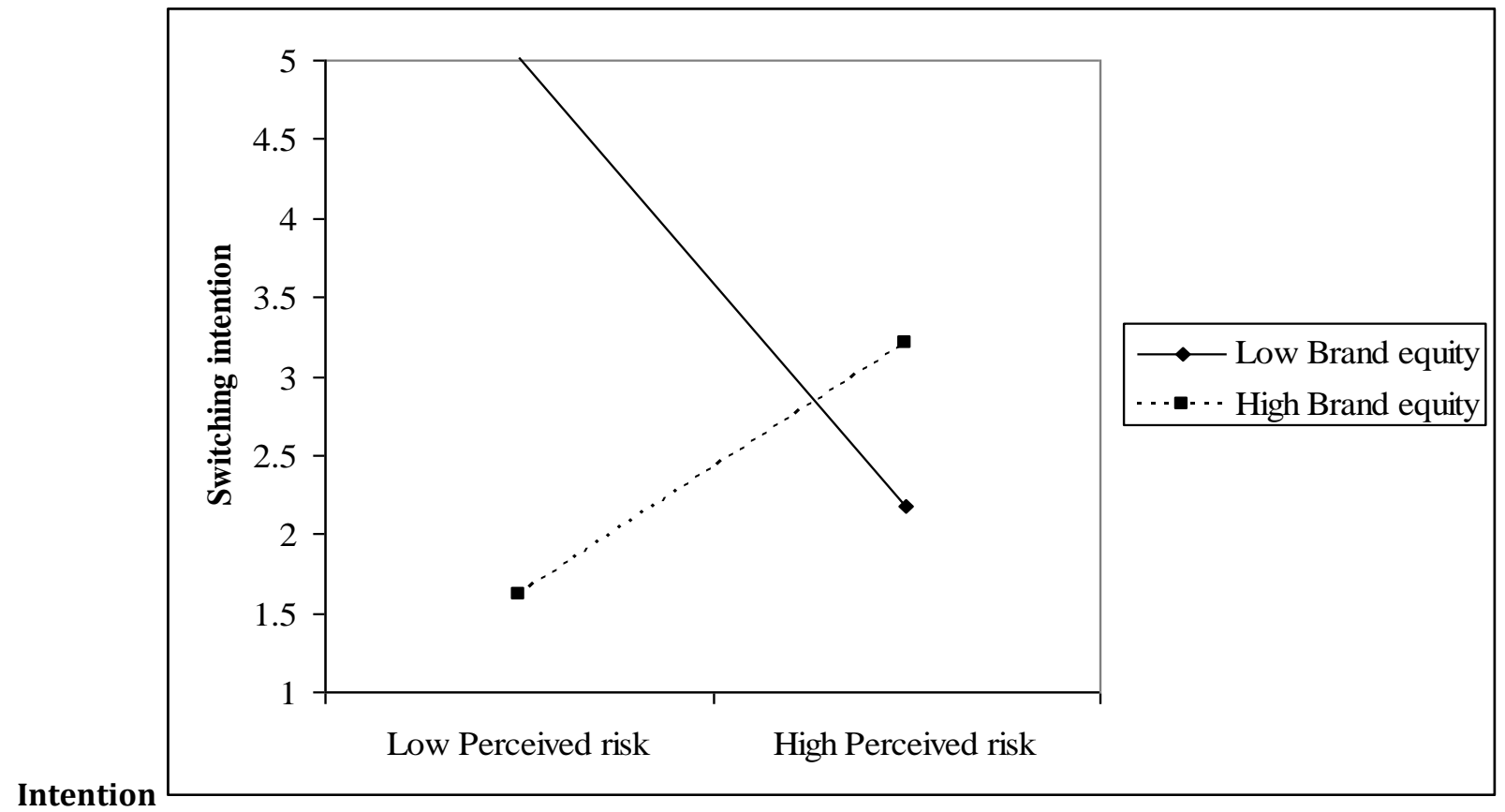

Discussion: Due to the fact that growing global competition has led to increasing pressure to improve the efficiency and effectiveness of both marketing and procurement efforts in business-to-business (B2B) markets (Ng, 2010). Industrial trade shows (B2B trade shows) are becoming increasingly important for sellers and buyers (Godar \& O'Connor, 2001). This study contributes to the literature of trade fairs, especially industrial trade fairs. In contrast to the majority of literature on exhibition performance, this study approached the issue from the standpoint of negative factors. This study also explored the effects of fair visitors' perceived risk on their purchase postponement and switching intention, and further examined the moderating role of exhibitors' brand equity. The analytical interpretation and practical implications of this study have high reference value to exhibitors of international mechanical fairs.

\section{Conclusion}

As expected, the higher fair visitors' perceived risk is, the more their purchase postponement and switching intention will be. Besides, when buyers face high brand equity exhibitors' products if they perceive low risk on use, they will tend not to delay purchase and switch suppliers; in contrast, if buyers perceive high risk on use, they will tend to delay purchase and switch suppliers. Finally, when buyers face low brand equity exhibitors' products if they perceive low risk on use, they will tend to delay purchase and switch suppliers; in contrast, if buyers perceive high risk on use, they will tend not to delay purchase and switch suppliers. 
Managerial Implications: Although the concept of perceived risk has received relatively less attention (Snoj, Korda \& Mumel, 2004), it is an important factor influencing consumers' purchase intention. Our analytic results indicate that fair visitors' perceived risk on exhibitors' products will positively affect their purchase postponement and switching intention. Thus, exhibitors must put in extra effort to reduce buyers' perceived risk. For industrial buyers, they are often concerned about the past manufacturing experience, product sales, and after-sales maintenance service of suppliers. This study suggests that exhibitors provide the above information to visitors. In particular, they can service local buyers through local dealers or distributors with different capabilities in order to lower buyers' perceived risk and shorten the after-sales service time to meet buyers' expectation.

Moreover, this study discovered that when buyers face high brand equity exhibitors' products if they perceive low risk on use, they will tend not to delay purchase and switch suppliers. When the risk on use is low, buyers will generally have higher expectations of the high brand equity exhibitors' products and are unwilling to shoulder the higher switching risk. Therefore, buyers are less likely to have purchase postponement or switching intention. In contrast, if buyers perceive high risk on use, they are more likely to have purchase postponement and switching intention. In the case of high risk on use, buyers would consider whether it is worthwhile to pay a high price to purchase high brand equity exhibitors' products given a similar risk level. They would look for replacement suppliers or products in the trade fair and thus their purchase postponement and switching intention are high.

Thus, this study suggests that high brand equity exhibitors design different marketing strategies for these two types of buyers. For low perceived risk buyers, high brand equity exhibitors can, given cost considerations, use discounts to respond to the competition and let buyers have room for bargain in order to raise the probability of buyers' order placement. For high perceived risk buyers, high brand equity exhibitors must proactively provide buyers with the information on the strength and weakness of their products compared to those offered by their competitors. Also, exhibitors should emphasize their comprehensive after-sales service and product warranty period in an effort to decrease these buyers' perceived risk.

In terms of customers' product use, brand equity can achieve the feelings of utility increase and added value (Farquhar, 1989; Yoo \& Donth, 2001). However, this does not mean that low brand equity exhibitors do not have a chance to sell their products. This study finds that when buyers face low brand equity exhibitors' products if they perceive low risk on use, they will tend to delay purchase and switch suppliers. When buyers perceive low risk on use, they generally have low expectations on low brand equity exhibitors' products. Since the risk on use of the product is very low, buyers hope to find a replacement supplier or product in the trade show. Therefore, they tend to delay their purchase. Also, if they find products with much lower price in the trade fair, they may intend to switch suppliers. In contrast, if the risk on use is very high, the intention of 
purchase postponement and switching suppliers is low. When buyers perceive high risk on use, the search for high brand equity exhibitors is not without risk and buyers have to make purchases at a higher price. Therefore, they are unwilling to switch suppliers. Also, they have to bear switching risk. As a result, they are less likely to postpone purchase and switch suppliers.

Therefore, this study suggests that low brand equity exhibitors design different marketing strategies for these two types of buyers. For low perceived risk buyers, low brand equity exhibitors' products are unable to provide visitors with additional information such as past manufacturing experience and product sales results, as well as comprehensive after-sales service. Therefore, exhibitors have to focus on pricing as the main form of competition. These exhibitors have to emphasize on their past manufacturing, areas that they could be trusted, and product sales results. Also, according to buyers' needs, they should provide customized after-sales service and proactively provide information on homogenous and replaceable products in order to reduce buyers' probability of purchase postponement and switching intention. For high perceived risk buyers, low brand equity exhibitors should use a low-price strategy to attract buyers. Also, they should convince buyers through technically advanced dealers and distributors. Especially, they should lower buyers' perceived risk and shorten after-sales service time in order to meet buyers' expectations. Furthermore, they should give buyers a feeling that the products they purchase are well worth the value so as to reduce the probability of buyers' purchase postponement and switching intention. The above research results differ somewhat from the consumer behaviors of general consumption products. Relative to consumer products, industrial products carry higher price tags and the risk associated with a wrong purchase is high and thus buyers have to strike a balance between price and risk. These are the reasons why the buyers' behaviors are different than those of general consumption.

Limitations: This study adopts Sinha \& Batra (1999) single-dimension scale to measure perceived risk. However, Jacoby \& Kaplan (1972) distinguished perceived risk into: performance risk, financial risk, social risk, physical risk and psychological risk. Thus, this study suggests future research to adopt the above dimensions in examining exhibitors' perceived risk in international industrial fairs. This study adopts Yoo \& Donth (2001) single-dimension scale to measure brand equity. However, previous studies have used other variables such as brand associations, perceived quality, and brand loyalty to measure brand equity (e.g., Biedenbach, Bengtsson \& Wincent, 2011). Therefore, this study suggests future research to adopt the above dimensions in examining exhibitors' brand equity in international industrial fairs. In addition, this study did not study the nationalities of the exhibitors and buyers. This research recommends that future studies follow the research framework of this study and conduct a pair-wise comparison between exhibitors and buyers in order to examine the differences in the research results from different nationality pairing. 


\section{References}

Aaker, D. A. (1991). Managing brand equity. New York: Free Press.

Aaker, D. A. (1995). Building strong brand (1st Ed.). New York: The Free Press.

Barwise, P. (1993). Brand equity: Snark or boojum. International Journal of Research in Marketing, 10(1), 93-104.

Bauer, R. A. (1960). Consumer Behavior as Risk Taking. In R. Hancock (Ed.), Dynamic Marketing for a Changing World (pp. 389-398). Chicago: American Marketing Association.

Biedenbach, G., Bengtsson, M. \& Wincent, J. (2011). Brand equity in the professional service context: Analyzing the impact of employee role behavior and customer-employee rapport. Industrial Marketing Management, 40(7), 1093-1102.

Blythe, J. (2010). Trade fairs as communication: A new model. Journal of Business \& Industrial Marketing, 25(10), 57-62.

Campbell, M. C. \& Goodstein, R. C. (2001). The moderating effect of perceived risk on consumers' evaluations of product incongruity: Preference for the norm. Journal of Consumer Research, 28(3), 439-449.

Cox, D. F. (1967). Risk Taking and Information Handling in Consumer Behavior. In D. F. Cox (Ed), Risk Taking and Information Handling in Consumer Behavior (pp. 604-639). Boston: Harvard University Press.

Dekimpe, M. G., Francois, P., Gopalakrishna, S., Lilien, G. L. \& Van den Bulte. C. (1997). Generalizing about trade show effectiveness: A cross-national comparison. Journal of Marketing, 61(4), 55-64.

Dowling, G. R. \& Staelin, R. (1994). A model of perceived risk and intended risk-handling activity. Journal of Consumer Research, 21(1), 119-134.

Farquhar, P. (1989). Managing brand equity. Marketing Research, 1(3), 24-33.

Featherman, M. S. \& Pavlou, P. A. (2003). Predicting e-services adoption: A perceived risk facets perspective. International Journal of Human-Computer Studies, 59(4), 451-474.

Fornell, C. \& Larcker, D. F. (1981). Evaluating structural equation models with unobservable variables and measurement error. Journal of Marketing Research, 18(1), 39-50.

Fraedrich, J. P. \& Ferrell, O. C. (1992). The impact of perceived risk and moral philosophy type on ethical decision making in business organizations. Journal of Business Research, 24(4), 283-295.

Godar, S. H. \& O'Connor, P. J. (2001). Same time next year-Buyer trade shows motives. Industrial Marketing Management, 30(1), 77-86.

Gopalakrishna, S. \& Lilien, G. L. (1995). A three-stage model of industrial trade shows performance. Marketing Science, 14(1), 22-42.

Gopalakrishna, S., Lilien, G. L., Williams, J. D. \& Sequeira, I. K. (1995). Do trade shows pay off? Journal of Marketing, 59(3), 75-83.

Grewal, D., Iyer, G. R., Gotlieb, J. \& Levy, M. (2007). Developing a deeper understanding of post-purchase perceived risk and behavioral intentions in a service setting. Journal of the Academy of Marketing 
Science, 35, 250-258.

Hansen, K. (2004). Measuring performance at trade shows: Scale development and validation. Journal of business Research, 57(1), 1-13.

Harder, J. W. (1991). Equity theory versus expectancy theory: The case of major league baseball free agents. Journal of Applied Psychology, 76(3), 458-464.

Hung, C. C., Lee, C. H. \& Zhuang, W. L. (2015). The effect of exhibitors' brand equity on visitors' purchase intention: Moderating role of 3D experiential marketing. Information Management and Business Review, 7(2), 100-112.

Jacoby, J. \& Kaplan, L. B. (1972). The Components of Perceived Risk. In M. Venkatesan (ed.), Advance in Consumer Research (pp.383-393), Chicago: Association for Consumer Research.

Keaveney, S. M. (1995). Customer switching behavior in service industries: An exploratory study. Journal of Marketing, 59(2), 71-82.

Keller, K. L. (1993). Conceptualizing, measuring, managing customer-based brand equity. Journal of Marketing, $57(1), 1-22$.

Kerin, R. A. \& Cron, W. L. (1987). Assessing trade show functions and performance: An exploratory study. Journal of Marketing, 51(3), 87-94.

Kim, J. H. \& Hyun, Y. J. (2011). A model to investigate the influence of marketing-mix efforts and corporate image on brand equity in the IT software sector. Industrial Marketing Management, 40(3), 424-438.

Kirchgeorg, M., Jung, K. \& Klante, O. (2010). The future of trade show: Insights from a scenario analysis. Journal of Business \& Industrial Marketing, 25(4), 301-312.

Kotler, P. \& Keller, K. L. (2009). Marketing management (13th Ed.). Upper Saddle River, NJ: Prentice Hall.

Lee, C. K., Lee, M. \& Yoon, S. H. (2013). Estimating the economic impact of convention and exhibition businesses, using a regional input-output model: A case study of the Daejeon Convention Center in South Korea. Asia Pacific Journal of Tourism Research, 18(4), 330-353.

Lee, C. H. \& Kim, S. Y. (2008). Differential effects of determinants on multi-dimensions of trade show performance: By three stages of pre-show, at-show, and post-show activities. Industrial Marketing Management, 37(7), 784-796.

Li, L. Y. (2006). Relationship learning at trade shows: Its antecedents and consequences. Industrial Marketing Management, 35(2), 166-177.

Li, L. Y. (2007). Marketing resources and performance of exhibitor firms in trade shows: A contingent resource perspective. Industrial Marketing Management, 36(3), 360-370.

Liao, C. C., Lin, H. N. \& Liu, Y. P. (2010). Predicting the use of pirated software: A contingency model integrating perceived risk with the theory of planned behavior. Journal of Business Ethics, 91(2), 237-252.

Mitchell, T. R. \& Biglan, A. (1971), Instrumentality theories: current uses in psychology. Psychological Bulletin, 76(6), 432-454. 
Mitchell, V. W. (1992). Understanding consumers' behavior: Can perceived risk theory help? Management Decision, 30(3), 26-31.

Ng, E. (2010). Understanding B2B supplier selection relationships: The case of Taiwan agribusinesses. Journal of Business-to-Business Marketing, 17(2), 149-172.

Noble, C. H. \& Mokwa, M. P. (1999). Implementing marketing strategies: Developing and testing a managerial theory. Journal of Marketing, 63(4), 57-73.

Oliver, R. L. \& Swan, J. E. (1989). Consumer perceptions of interpersonal equity and satisfaction in transactions: A field survey approach? Journal of Marketing, 53(2), 21-35.

Pavlou, P. A. (2003). Consumer acceptance of electronic commerce: Integrating trust and risk with the technology acceptance model. International Journal of Electronic Commerce, 7(3), 101-134.

Ping, R. A. (1994). Does satisfaction moderate the association between alternative attractiveness and exit intention in a marketing channel? Journal of the Academy of Marketing Science, 22(4), 364-371.

Podsakoff, P. M., MacKenzie, S. B., Lee, J. Y. \& Podsakoff, N. P. (2003). Common method biases in behavioral research: A critical review of the literature and recommended remedies. Journal of Applied Psychology, 88(5), 879-903.

Seringhaus, F. H. R. \& Rosson, P. J. (2001). Firm experience and international trade fairs. Journal of Marketing Management, 17(7-8), 877-901.

Sinha, I. \& Batra, R. (1999). The effect of consumer price consciousness on private label purchase. International Journal of Research in Marketing, 16(3), 237-251.

Sloot, L. M. \& Verhoef, P. C. (2008). The impact of brand delisting on store switching and brand switching intentions. Journal of Retailing, 84(3), 281-296.

Snoj, B., Korda, A. P. \& Mumel, D. (2004). The relationships among perceived quality, perceived risk and perceived product value. Journal of Product and Brand management, 13(3), 156-167.

Sweeney, J. C., Soutar, G. N. \& Johnson, L. W. (1999). The role of perceived risk in the quality-value relationship: A study in a retail environment. Journal of Retailing, 75(1), 77-105.

Tanner, J. F. (2002). Leveling the playing field: Factors influencing trade show success for small companies. Industrial Marketing Management, 31(3), 229-239.

Vroom, V. C. (1964). Work and motivation. New York, NY: John Wiley \& Sons.

Walsh, G., Hennig-Thurau, T. \& Mitchell, V. W. (2007). Consumer confusion proneness: Scale development, validation, and application. Journal of Marketing Management, 23(7-8), 697-721.

Wu, K., Vassileva, J., Noorian, Z. \& Zhao, Y. (2015). How do you feel when you see a list of prices? The interplay among price dispersion, perceived risk and initial trust in Chinese C2C market. Journal of Retailing and Consumer Services, 25, 36-46.

Yoo, B. \& Donth, N. (2001). Developing and validating multidimensional consumer-based brand equity scale. Journal of Business Research, 52(1), 1-14. 